\title{
Production of human papillomavirus and modulation of the infectious program in epithelial raft cultures
}

\author{
Sheila C. Dollard, ${ }^{1}$ Jeffrey L. Wilson, ${ }^{1}$ Lisa M. Demeter, ${ }^{2}$ William Bonnez, ${ }^{2}$ Richard C. Reichman, ${ }^{2}$ \\ Thomas R. Broker, ${ }^{1}$ and Louise T. Chow ${ }^{1,3}$ \\ ${ }^{1}$ Department of Biochemistry and ${ }^{2}$ Department of Medicine, Infectious Diseases Unit, University of Rochester School of \\ Medicine and Dentistry, Rochester, New York 14642 USA
}

\begin{abstract}
Human papillomaviruses trophic for anogenital epithelia cause benign warts, and certain genotypes are closely associated with cervical neoplasia. By using our modifications of the epithelial raft culture system, we were able to recapitulate and modulate the infectious program of a papillomavirus in vitro for the first time. Small pieces of a condyloma containing human papillomavirus type 11 were explanted onto a dermal equivalent consisting of a collagen matrix with fibroblasts and were cultured at the medium-air interface. The infected stem cells proliferated rapidly across the matrix, stratified, and differentiated, as judged by histology. The results correlated with the state of epithelial differentiation, which, in turn, was dependent on the type of fibroblast in the matrix. Under conditions where the epithelial outgrowth underwent terminal differentiation, the entire productive program took place, leading to virion assembly. In contrast, using an alternative condition where the outgrowth failed to achieve terminal differentiation, only the E-region RNAs from the E1 promoter accumulated to any appreciable extent. The proliferating cell nuclear antigen was induced in the differentiated suprabasal cells in the productive cyst growth, which also exhibited high copy viral DNA and abundant E6-E7 RNAs. Comparable cells in the nonproductive cyst outgrowth were negative for all three. These results suggest that the E6 and E7 proteins may play a role in establishing a cellular environment conducive to vegetative viral replication. The culture conditions described should be useful for genetic analysis of this family of important human pathogens and for testing potential pharmacological agents.
\end{abstract}

[Key Words: HPV-11; keratinocyte differentiation; transcriptional program; replication; virion production]

Received March 5, 1992; revised version accepted April 23, 1992.

Human papillomaviruses (HPVs) are small DNA tumor viruses (see Fig. 1) and are the etiological agents for warts of cutaneous or mucosal epithelia (de Villiers 1989). HPV types 16 and 18 are frequently associated with high-grade cervical and penile intraepithelial neoplasias and cancers, whereas types 6 and 11 are commonly found in benign genital warts (condylomata acuminata) and laryngeal papillomas. In vivo, productive viral infection occurs only in squamous epithelia undergoing terminal differentiation. Viral mRNA and DNA are present at low copy number in the infected stem cells and are usually not detectable. Viral transcription increases with cellular differentiation. Transcripts from the E1 promoter are the first to be detected and remain more abundant in all cell strata than those from the E6 promoter. Viral DNA replication, capsid protein synthesis, and assembly of progeny virions take place in a small fraction of superficial differentiated cells (Stoler et al. 1989). Many molecular features of HPVs have been elucidated, including

${ }^{3}$ Corresponding author. the complex structures of the overlapping mRNAs (Rotenberg et al. 1989a,b; Smotkin et al. 1989; Doorbar et al. 1990; Palermo-Dilts et al. 1990; Chiang et al. 1991; Rohlfs et al. 1991), the regulation of the E6 promoter by host and viral proteins (for review, see Sousa et al. 1990) and the requirements of extrachromosomal viral DNA replication (Ustav and Stenlund 1991; Yang et al. 1991; Chiang et al. 1992). However, the control of other viral transcription units and the functions of many viral proteins in the productive cycle have remained largely undefined because no papillomavirus has been propagated in cell culture.

The mucosotrophic HPVs produce few virions in vivo. Nonetheless, HPV-11 has been propagated successfully in neonatal tissues implanted in athymic or nude mice (Kreider et al. 1987). Specifically, human foreskin chips experimentally infected with HPV-11 and implanted under the renal capsule of athymic mice develop into cysts that are indistinguishable from patient condylomata in morphology and in patterns of viral activity (Stoler et al. 1990). The virions recovered can be serially passaged in foreskin xenografts in nude mice. HPV-16 virions have 
also been visualized by electron microscopy in a cell line derived from a patient biopsy after being grafted onto the flank of a nude mouse (Sterling et al. 1990). Such transplant systems are not readily amenable to genetic and biochemical studies because it has not been possible to initiate infection with cloned DNA.

Primary epithelial cells can be propagated in vitro in the presence of fibroblasts. Although the resulting cell sheets have been used successfully for autologous skin grafts for burn patients, their morphology is very different from native epithelium, indicating that proper cellular differentiation did not take place (Compton et al. 1989|. When HPV-1 virions recovered from plantar warts are used to infect monolayers of primary keratinocytes, viral DNA replication cannot be sustained and the genomes are quickly lost from the cells (Taichman and LaPorta 1987). Similarly, when HPV DNA is transfected into cultured primary keratinocytes, it is either lost or becomes integrated into the host chromosomes. Collectively, these results are consistent with the hypothesis that productive infection requires a cellular environment found only in properly differentiating squamous epithelium.

In recent years, a system dubbed the raft culture has been increasingly utilized by epithelial cell biologists and HPV virologists because it allows primary human foreskin keratinocytes to achieve stratification and differentiation morphologically similar to foreskin (Asselineau and Prunieras 1984; Kopan et al. 1987; for review, see Parenteau et al. 1991). In this system, dispersed primary keratinocytes are seeded on a dermal equivalent consisting of a porous collagen gel containing fibroblasts. At confluence, the assembly is raised to the medium-air interface. The keratinocytes stratify and exhibit a differentiated morphology, generating a living skin equivalent. This system has been used to study the influence of the E6 and E7 genes of high-risk HPV types on the morphological differentiation of keratinocytes (McCance et al. 1988; Blanton et al. 1991; Woodworth et al. 1992 and references therein). Recently, a cervical cell line containing episomal HPV-31b has been grown as a raft culture; some transcripts from the $\mathrm{E}$ and $\mathrm{L}$ regions were detected by Northern blot hybridization, and DNA replication was detected by in situ hybridization (Bedell et al. 1991). However there was no Ll capsid antigen detected. The question remained as to whether raft cultures can support the productive program of HPV or whether additional factors are required that can only be supplied by the infected individuals.

In this report we describe the first production of virions in vitro by using our variation of the conventional raft culture system. In addition, the infectious program was modulated under an alternative raft culture condition. These experiments suggest that the viral E6 and E7 proteins may have a role in vegetative DNA replication by reactivating host cell DNA replication machinery in cells that have exited from the cell cycle to undergo terminal differentiation, as was proposed previously on the basis of observations in condylomata (Stoler et al. 1989, 1990).

\section{Results}

\section{Experimental design}

A conventional raft culture is established with dispersed primary keratinocytes. We found that a few small chips of uninfected foreskin could also be used to initiate the culture. Basal cells from the foreskin epidermis proliferate across the dermal equivalent, stratify, and differentiate, generating a faithful epithelial equivalent. The fibroblasts in the explant do not migrate (S. Dollard, J. Wilson, T. Broker, and L. Chow, unpubl.).

To determine whether the raft culture system can support papillomavirus production, we explanted pieces of HPV-11-induced condylomatous cysts recovered from nude mice on collagen matrices. Several $2-\mathrm{mm}^{2}$ chips of cyst tissue were placed on the surface of a dermal equivalent containing primary neonatal foreskin fibroblasts or 3T3 A31 mouse fibroblasts and were exposed to air from the outset, as described in Materials and methods. Basal cells grew rapidly from the cyst explants and covered the remaining collagen surface. The outgrowth stratified and differentiated by 2 weeks. Portions of the cultures were harvested at several time points up to 6 weeks, fixed in buffered $10 \%$ formalin, and embedded in paraffin. Fourmicrometer serial sections were stained for histology, or used for immunocytochemical analysis of viral or host proteins or in situ hybridization with ${ }^{35} \mathrm{~S}$ - or ${ }^{3} \mathrm{H}$-labeled riboprobes for the detection of DNA and individual RNA messages (Fig. 1) (Stoler et al. 1989). Four cysts were explanted and analyzed. The results of these experiments are discussed below.

\section{Limited E-region transcription in raft cultures prepared with primary human foreskin fibroblasts}

In four experiments, primary neonatal foreskin fibroblasts were used in the dermal equivalent because they reconstituted a homologous human dermal-epidermal system. After 9 days, one or two layers of epithelial outgrowth from the cyst chips covered the surface of the matrix (Fig. 2A). The original tissue as well as the outgrowth contained easily detectible levels of viral RNA

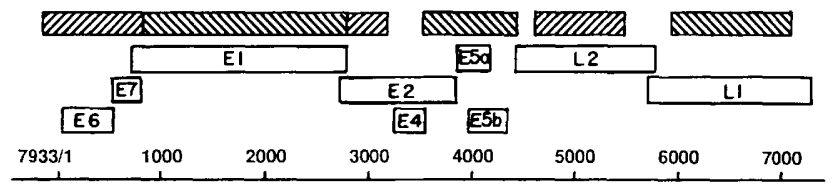

Figure 1. Genetic organization of HPV-11 and exon-specific riboprobes. The circular genome of $7933 \mathrm{bp}$ is represented in a linear form. ORFs deduced from the DNA sequence are drawn as open boxes. E-region ORFs encode proteins that are required for and regulate viral DNA replication and mRNA transcription and result in pathogenic responses in host cells. L-region ORFs encode capsid proteins. Hatched boxes correspond to segments of the genome used to synthesize antisense riboprobes for the detection of individual mRNA exons. Whole genomic antisense or sense riboprobes were used to detect total viral RNA or DNA, respectively. 


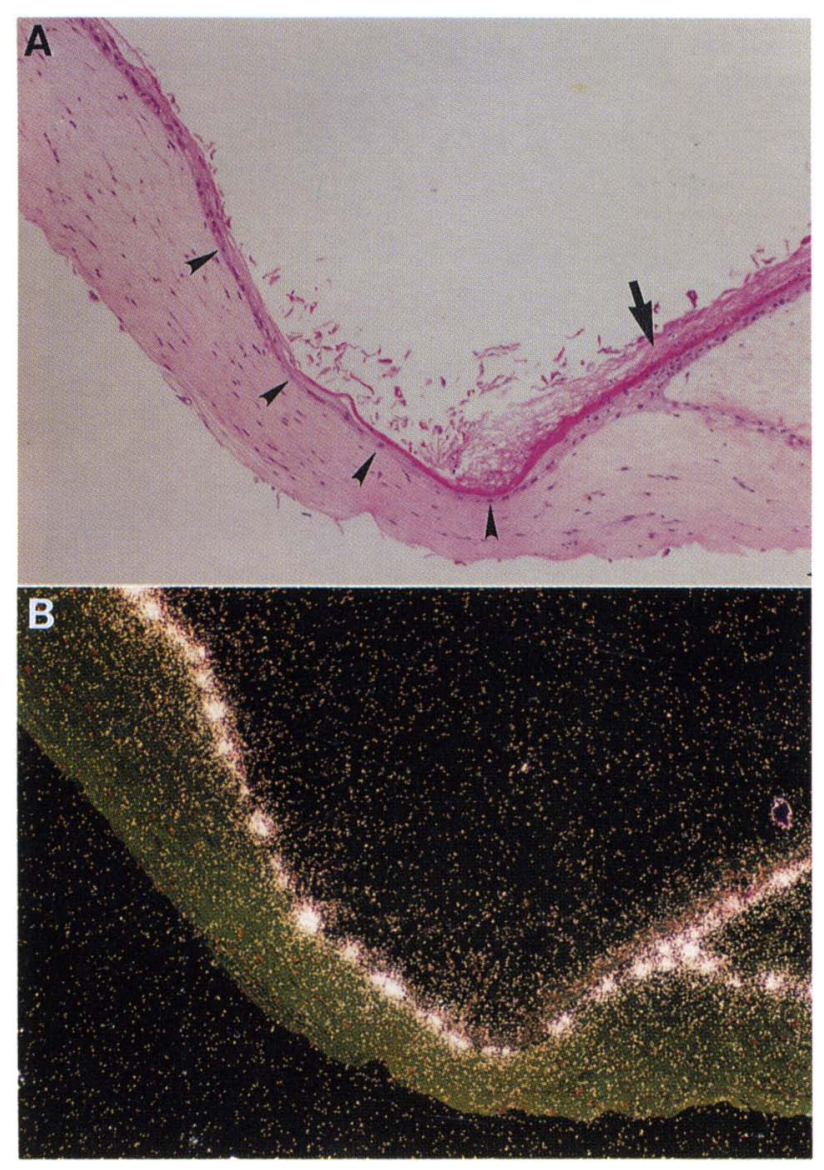

Figure 2. HPV-11 mRNA expression in a 9-day cyst explant raft culture supported by human fibroblasts. $(A) \mathrm{H} \&$ E-stained section. The boundary between keratinocyte outgrowth to the left and the original cyst tissue to the right is marked by an arrow. Epithelial cells also migrated underneath the original tissue chip. Arrowheads mark basal cells in the outgrowth. $(B)$ Dark-field micrograph of an adjacent section after in situ hybridization with ${ }^{35} \mathrm{~S}$-labeled antisense strand E4-E5 probe (sp. act. $2 \times 10^{8} \mathrm{dpm} / \mu \mathrm{g}$ ). Signals appear as white grains.

from the E4-E5 region (Fig. 2B). Some cells contained weak signals from the E1 and E2 probes, most of which were nuclear. No other probe generated a detectable signal in the outgrowth (data not shown). By 3 weeks, the epithelial outgrowth was well stratified (Fig. 3A). In situ hybridization revealed patterns of viral gene expression similar to the 9-day culture, except that the E4-E5 signals were stronger in the morphologically more differentiated upper layers than the lower strata (Fig. 3F). No E6-E7 signal was detected (Fig. 3C). Small amounts of E1 and E2 mRNAs also existed (Fig. 3D,E), but the majority of the signals were nuclear, which is better visualized in bright-field illumination or when ${ }^{3} \mathrm{H}$-labeled riboprobes are used (data not shown). Sense-strand riboprobes did not detect DNA amplification in three of four experiments (Fig. 3B). In the fourth experiment, relatively low E6-E7 RNA signals and minimal DNA replication were detected in a small fraction of the cells in the upper strata. There were no transcripts from the $\mathrm{L}$ region or $\mathrm{Ll}$ capsid antigen in any of the four experiments (data not shown).

On the basis of the HPV-11 mRNA structures (Chow et al. 1987b; Rotenberg et al. 1989a,b), the abundant transcripts may correspond to the Eli ` $\mathrm{E} 4$ mRNA (spliced between nucleotide positions 847 and 3325) (Nasseri et al. 1987) or the putative E5 mRNA (spliced between nucleotide positions 847 and 3377) (Chiang et al. 1991). Both messages are generated from the El promoter, which initiates transcription near nucleotide 700, upstream from the E1 open reading frame (ORF) (Nasseri et al. 1987, Ward and Mounts 1989). The majority, but not all, of the E1 and E2 signals were nuclear and can be attributed to the primary transcript or to residual intron sequences removed during the processing of the E4 or E5 mRNAs, as has been noted previously in condylomata and low-grade intraepithelial neoplasias (Chow et al. 1987a; Broker et al. 1989; Stoler et al. 1989, 1990, 1992).

Using polymerase chain reaction (PCR) with primers flanking the splice sites, amplification of the first-strand cDNAs generated from $4-\mu \mathrm{m}$ paraffin sections of the 3-week outgrowth demonstrated similar amounts of both the Eli ${ }^{\wedge} \mathrm{E} 4$ and the E5 messages (Fig. 4). However, we did not detect E4 protein by immunocytochemistry using rabbit polyclonal antisera, probably owing to low abundance.

\section{Complete viral productive program of HPV in raft cultures prepared with mouse 3 T3 A31 cells}

Recent studies in our laboratory have shown that conventional raft cultures of dispersed primary human foreskin keratinocytes supported by BALB/c 3T3 A31 mouse fibroblasts achieved molecular differentiation closely resembling foreskin. In contrast, those supported by primary neonatal foreskin fibroblasts did so more slowly and not to the same extent, as judged by the mRNA and protein expression patterns of the terminal differentiation markers keratin 1 and profilaggrin (Wilson et al. 1992).

The limited viral activities in the cyst explant cultures prepared with primary human fibroblasts might be attributed to several causes, including a lack of terminal differentiation in the raft cultures, a deficiency in additional factors that are supplied by living hosts but are not present in cultures, or the short duration of the experiment relative to natural infections, which may well have an extended latency period. To examine the first two possibilities, we placed small tissue pieces from two of the same four HPV-11 cysts on collagen matrices containing mouse 3T3 A31 cells.

Complete viral transcription and replication programs leading to virion assembly took place by 3 weeks in the keratinocyte outgrowths. Most exon-specific probes generated intense cytoplasmic and nuclear signals, with the E4-E5 RNAs being most abundant (Fig. 5C-H). The majority of the E1 and E2 signals remained nuclear (Fig. 5D,E). The E4-E5 RNA signals were at least 100 times higher than those in the nonproductive cyst raft cultures 

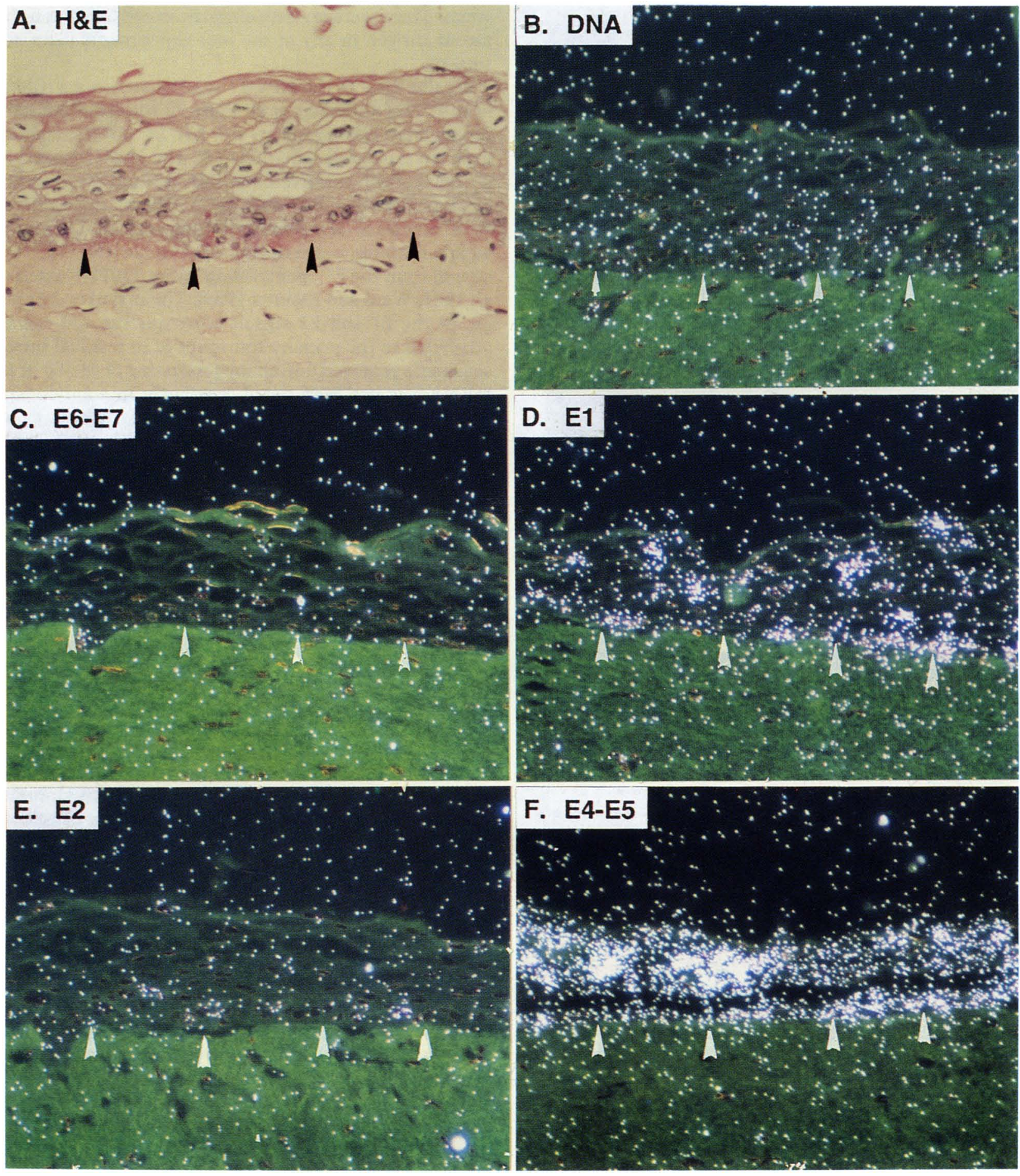

Figure 3. Limited viral gene expression in a 3-week cyst explant raft culture supported by primary neonatal foreskin keratinocytes. $(A) \mathrm{H} \& \mathrm{E}$, histology; $(B) \mathrm{DNA}(C) \mathrm{E} 6-\mathrm{E} 7 ;(D) \mathrm{E} 1 ;(E) \mathrm{E} 2 ;(F) \mathrm{E} 4-\mathrm{E} 5$. Arrowheads mark basal cells in the outgrowth. The majority of the E1 and E2 signals are confined to spots the size of a nucleus (as deduced from $A$ ), suggesting nuclear localization, and most likely represent primary transcripts or introns derived from the E4-E5 mRNAs. Only minor signals are cytoplasmic, as expected for mRNA.

(cf. Figs. 5F and 3F). The amount of viral mRNA increased dramatically with epithelial differentiation. A subset of the cells expressing L1 mRNA also contained Ll capsid antigen, as shown by immunocytochemistry
(Fig. $5 \mathrm{H}$, )). Some of the E4 protein-containing cells in the outgrowth were also positive for $\mathrm{L} 1$ antigen (Fig. 3I,J), as has been observed previously in condylomata (Crum et al. 1990; T. Ho, D. Strike, L. Chow, and T. Broker, un- 


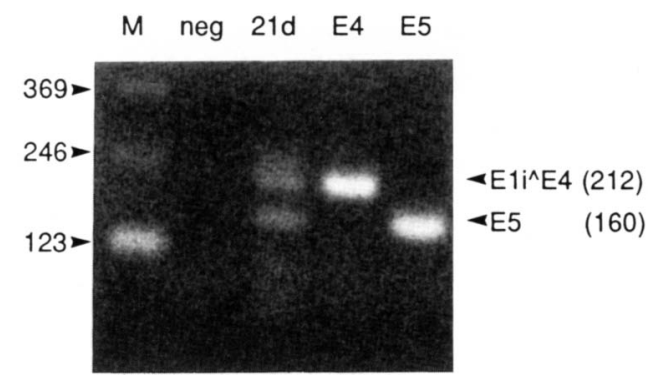

Figure 4. Coupled reverse transcriptase (RT)-PCR amplification of cDNAs of viral transcripts in paraffin sections. (Lane 1) $(123)_{n}$ bp ladder length markers; (lane 2) RT-PCR without tissue; (lane 3) 21-day raft outgrowth supported by primary human fibroblasts; (lanes 4,5) positive controls using E1i ${ }^{\wedge} \mathrm{E} 4$ and E5a cDNAs as templates.

publ.). Vegetative amplification of viral DNA occurred in some of the more differentiated cells throughout the outgrowth (Fig. 3B). Many of the cells positive for capsid antigen and viral DNA appeared koilocytotic, the hallmark of productive infection in vivo (Fig. 5A). These patterns of viral gene expression and DNA replication were virtually identical to those observed in patient and experimental condylomata.

An area of outgrowth from a paraffin section adjacent to sections positive for $L l$ antigen was examined by electron microscopy. Intranuclear viral particles were visualized (Fig. 6). The particles were electron dense, uniform in size, and measured $\sim 40 \mathrm{~nm}$ in diameter, within the reported range for positively stained papillomavirus virions observed in tissues (Dunn and Ogilvie 1968; Hills and Laverty 1979). The capsomeres are discernible in the inset of Figure 6. Thus, these particles were complete virions and not empty capsids or capsid protein aggregates that would not demonstrate these staining features.

State of differentiation in the outgrowth of cyst explant raft cultures

To assess the state of epithelial differentiation, in situ hybridization with epithelial differentiation-stage-specific riboprobes was carried out with serial sections of the same cyst explant raft cultures analyzed for viral expression in Figures 3 and 5. As with uninfected foreskin keratinocyte raft cultures (Wilson et al. 1992), the outgrowth of cyst explants supported by either primary human fibroblasts or mouse 3T3 A31 cells exhibited similar levels of K5 and K14 mRNAs, markers for basal cells, in the lower portions of the epithelium (Fig. 7E,F and data not shown), a pattern similar to patient condylomata (J.L. Wilson, M.H. Stoler, L.T. Chow, and T.R. Broker, unpubl.). However, only in the outgrowth supported by the mouse $3 \mathrm{~T} 3 \mathrm{~A} 31$ cells did we detect mRNAs of keratin 1, a marker for commitment to differentiation, and of profilaggrin, a marker for terminal differentiation (Fig. 7A-D). Both $\mathrm{K} 1$ and profilaggrin mRNAs are typically present in patient condylomata or normal foreskin epithelium (Wilson et al. 1992; J.L. Wilson, M.H. Stoler, L.T. Chow, and T.R. Broker, unpubl.).

\section{Discussion \\ Correlation of terminal differentiation with productive HPV infection}

By using a variation of the keratinocyte raft culture technique, we have achieved the first production of papillomavirus virions in vitro. In contrast, only low levels of E-region mRNAs originating from the $\mathrm{E} 1$ promoter were detected under an alternative raft culture condition. The two cultures included in the collagen matrices different fibroblasts that promoted epithelial differentiation to different extents (Fig. 7) (Wilson et al. 1992). The ability of cultures supported by mouse 3T3 A31 cells to undergo terminal differentiation may be responsible for the complete viral productive program. Differentiation-dependent productive infection has also been observed for polyomavirus in mouse teratocarcinoma cells (Fujimura et al. 1981). However, additional differences between these cultures, not yet identified, may also contribute to the dramatic difference in viral activities.

\section{Detection of early transcription}

In the case of other well-characterized DNA viruses such as adenoviruses, SV40, and polyomavirus, only early mRNAs are expressed under nonpermissive conditions (Tooze 1981). By analogy to these other systems, we propose that the HPV-11 transcripts E1, E2, E4, and E5 detected in the nonproductive cultures are early messages, although low levels of E6-E7 mRNA cannot be excluded. Only under permissive culture conditions is there a dramatic increase in the abundance of transcripts from the E1 and E6 promoters, elongation of transcription from the $\mathrm{E}$ region through the $\mathrm{L}$ region (Chow et al. 1987b; Rotenberg et al. 1989b), and vegetative DNA replication (Fig. 5). The enhanced transcription is probably a result of both promoter up-regulation and an increase in the number of viral DNA templates. Future mutational analysis would be required to confirm this hypothesis on the progression of viral gene expression.

The viral E1 and E2 proteins are necessary for episomal replication of BPV-1 and HPV-11 origin-containing plasmids (Ustav and Stenlund 1991; Yang et al. 1991; Chiang et al. 1992). The presence of low levels of E1 and E2 cytoplasmic transcripts (Fig. 3D,E) is consistent with the ability of the nonproductive epithelial outgrowth to maintain the viral genome for weeks, during which the cells continued to be renewed from below.

In the 9-day outgrowth where there was little or no stratification and the cells were basal-like, the dramatic RNA signals from the E4-E5 region (Fig. 2) were unexpected. Viral transcription is virtually undetectable in basal and parabasal cells of established condylomata (Chow et al. 1987a; Stoler et al. 1989, 1990) or in comparable cells in the productive outgrowth of the cyst explant raft cultures (cf. Figs. 2 and $5 F$ ). We speculate that this initial phase of the cyst explant cultures simulates 

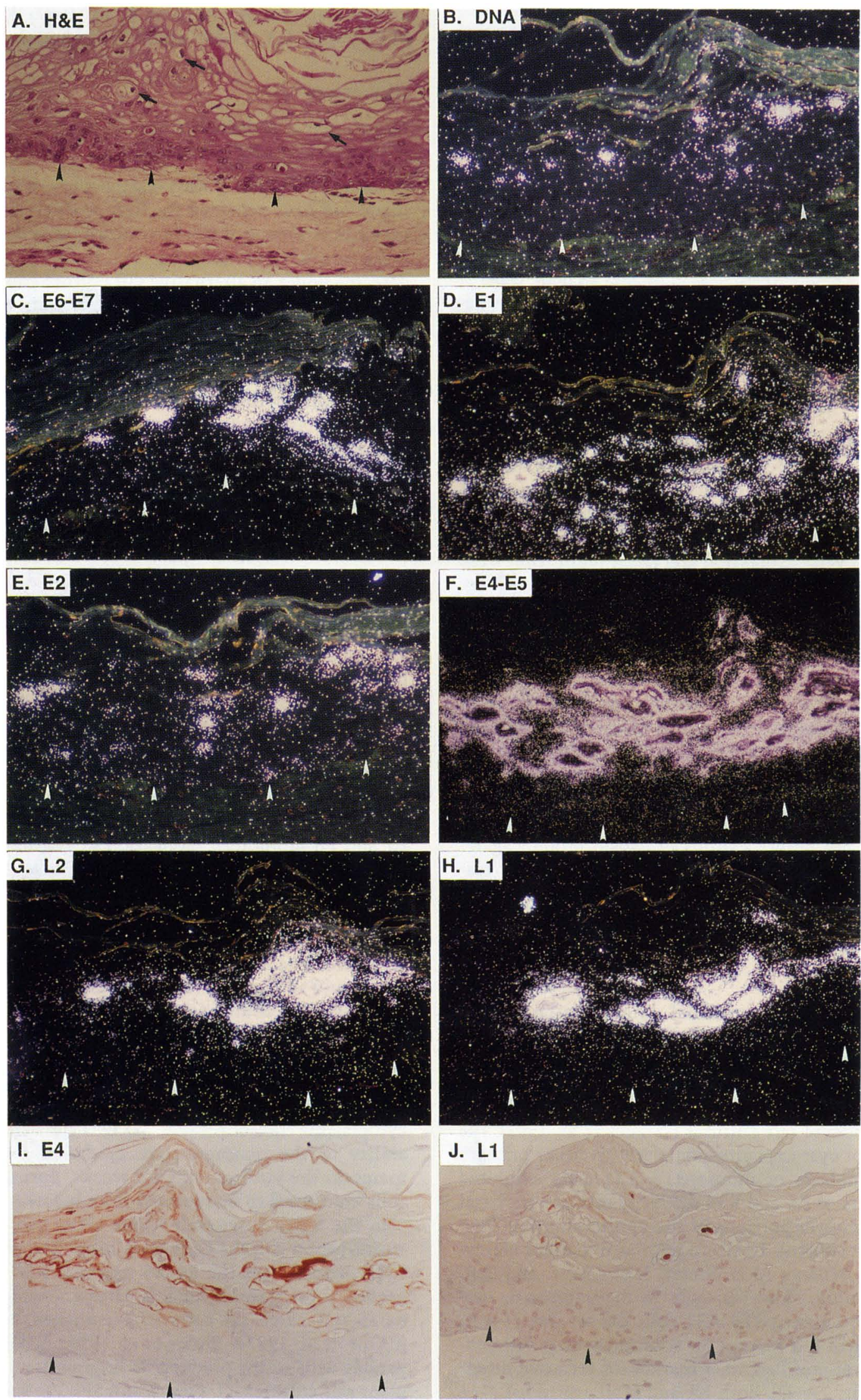

Figure 5. (See facing page for legend.) 


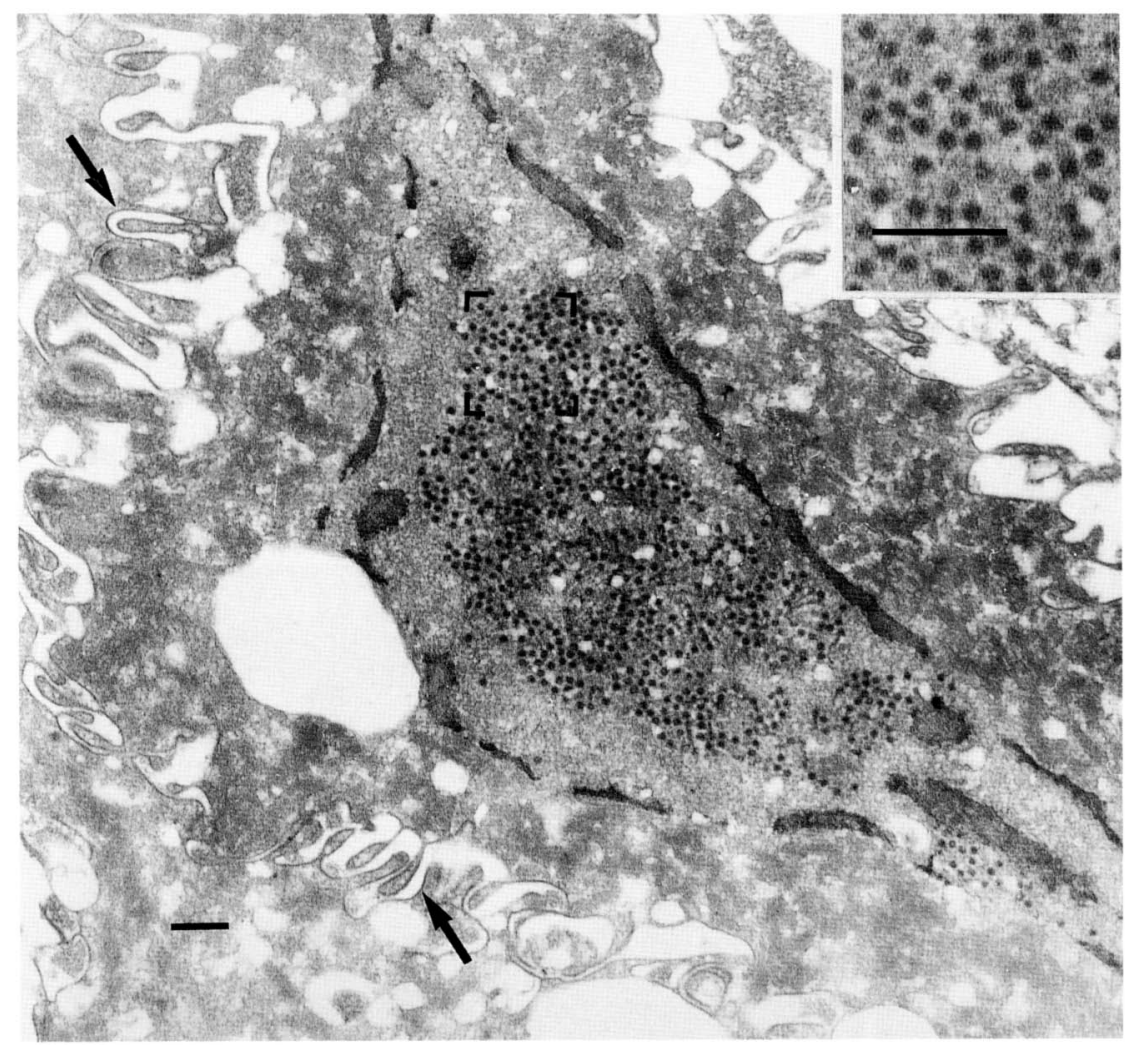

Figure 6. Virions in the outgrowth. Electron micrograph of a cell adjacent to the stratum corneum in the cyst outgrowth developed in a raft culture on a dermal equivalent containing mouse fibroblasts. Virus particles were observed in the nucleus. An area of outgrowth from a $4-\mu \mathrm{m}$ paraffin section adjacent to sections positive for $\mathrm{Ll}$ antigen was dissected under a light microscope, reembedded in plastic, ultrathin-sectioned, stained with uranyl acetate, and examined by transmission electron microscopy as described by Bretschneider et al. (1981). Interdigitation of cellular membranes (arrows) is characteristic of differentiated epithelial cells. (Inset) Enlargement $(2.5 \times)$, with corresponding regions marked with brackets. The bars measure $200 \mathrm{~nm}$. The often-cited 55-nm diameter of papillomavirus virions is based on negative staining of free particles, which will always appear larger than positively stained virions in tissue. the early stage of primary infection in wounded tissues that are undergoing regeneration or the reactivation of subclinical viral infections in patients following ablative therapy. E4 is an abundant cytoplasmic protein detected in cells as deep as parabasal cells up to the more differentiated L1 antigen-positive cells (Doorbar et al. 1986; Breitburd et al. 1987; Brown et al. 1988; Crum et al. 1990; T. Ho, D. Strike, L. Chow, and T. Broker, unpubl.). It is associated with cytokeratin filaments in transfected epithelial cell lines (Doorbar et al. 1991), but the significance of this association is not understood. That E5 should be transcribed in migrating basal cells is compatible with the observations that the BPV-1 papillomavirus E5, HPV-11 E5a, and HPV-16 E5 ORFs are "transforming genes" associated with elevated proliferation of murine fibroblasts or keratinocytes (Yang et al. 1985; Chen and Mounts 1990; Leptak et al. 1991).

\section{Potential roles of the $E 6$ and $E 7$ proteins in productive infection}

The E6 and E7 proteins of the high-risk HPVs can immortalize primary human keratinocytes when overex- pressed and thus have been interpreted to be early proteins (Hawley-Nelson et al. 1989; Münger et al. 1989a; Hudson et al. 1990; Halbert et al. 1991). However, among the four nonproductive cyst explants, only one had low levels of E6-E7 transcripts in the upper strata, coincidental with minimally detectable viral DNA replication. The rest had neither E6-E7 mRNA nor DNA signals (Fig. $3 B, C)$. The differentiation-associated accumulation of abundant E6 and E7 transcripts recapitulates the pattern seen in condylomata and in low-grade squamous intraepithelial lesions (Broker et al. 1989; Stoler et al. 1989, 1990, 1992; Beyer-Finkler et al. 1990/. Together with studies in other laboratories discussed below, these results suggest that the E6 and E7 proteins may play an important role in vegetative viral DNA replication, as do adenovirus (Ad) $\mathrm{E} 1$ proteins and SV40 $\mathrm{T}$ antigen ( $\mathrm{T}$-ag).

The Ad E1B and E1A proteins, the T-ag, and the E6 and E7 proteins of both high- and low-risk HPVs bind to the host tumor suppressor gene products p53 and the retinoblastoma susceptibility protein (pRB), respectively (Münger et al. 1989b; Barbosa et al. 1990; Werness et al. 1990; Crook et al. 1991). It has been shown that pRB, cyclin A and other cellular proteins sequester host transcription

Figure 5. The productive viral program in a 3-week cyst explant raft culture supported by mouse 3 T3 A31 fibroblasts. Pieces of tissue were from the same cyst as shown in Fig. 3. The same area of outgrowth in serial sections was photographed with bright-field illumination for histology $(A)$ and for immunocytochemistry $(I, J)$ or with dark-field illumination $(B-H)$ for in situ hybridization. Arrowheads mark basal cells in the outgrowth, as determined by comparison with bright-field photographs (not shown). (A) H \& E. A number of the cells in which viral DNA replication and Ll capsid antigen were detected were koilocytotic, with three such cells marked by arrows. $(B-H)$ The targets for the riboprobes are labeled on each panel. The apparent lack of E4-E5 ORF signals in the center of some of the cells $\langle F|$ is a result of extraordinarily high densities of silver grains, which eclipsed the scattered light beam. $(I)$ E4 protein; $(/) \mathbf{L} 1$ capsid antigen. 

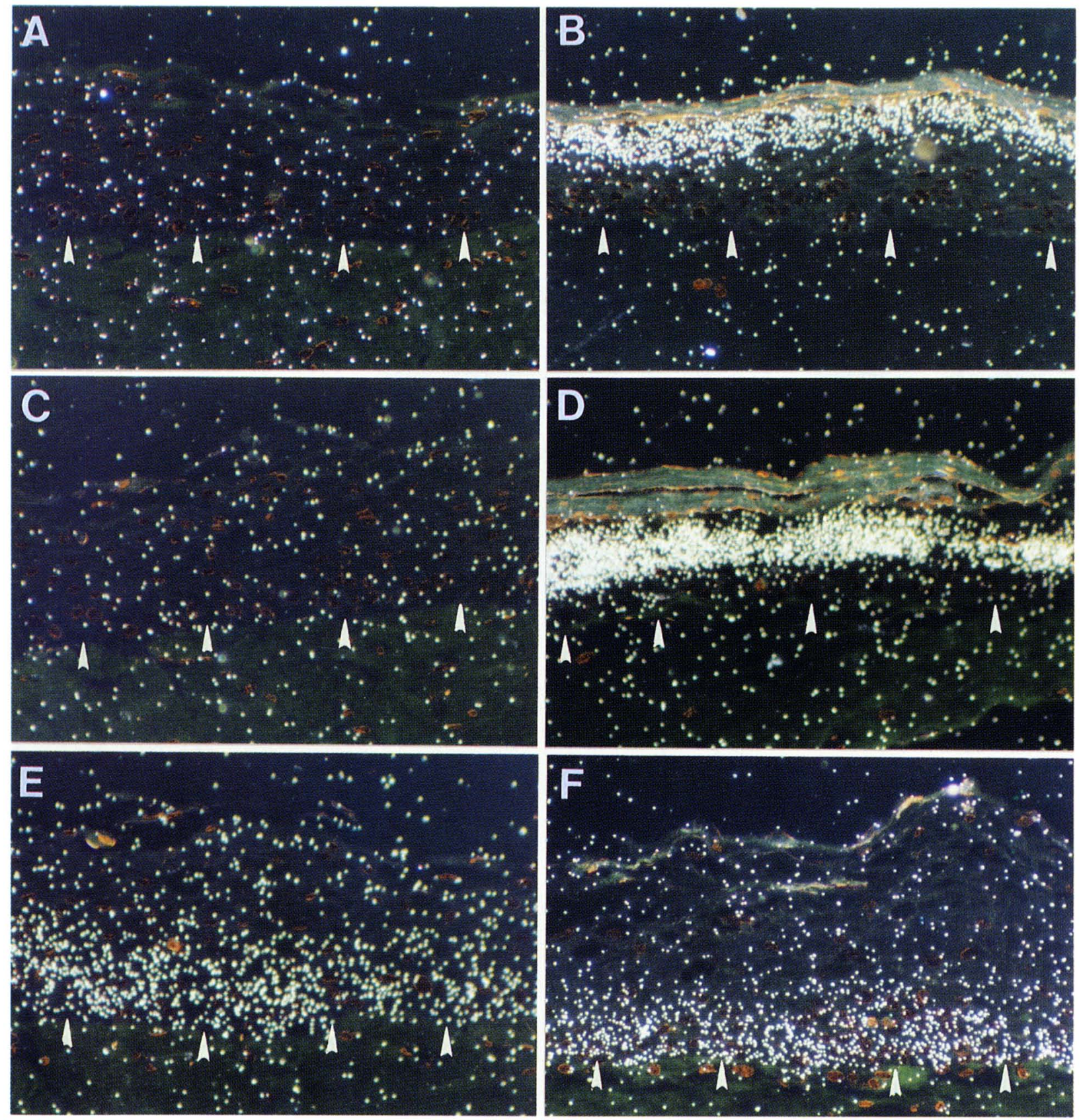

Figure 7. State of differentiation in the cyst outgrowth. Serial sections from the same experiments shown in Figs. 3 and 5 were used for in situ hybridization. $(A, C, E)$, outgrowth supported by primary human foreskin fibroblasts; $(B, D, F)$ outgrowth supported by mouse 3T3 A31 cells. Probes used are antisense RNA for human profilaggrin, a marker for terminal differentiation $(A, B)$; human keratin 1 , a marker for commitment to differentiation $(C, D)$; human keratin 5 , a marker for basal-like cells $(E, F)$. Similar results were also obtained with messge for K14, the partner of K5 (data not shown). Arrowheads indicate the basal cells.

factor E2F; and upon binding of the viral proteins, E2F is released from one or more inactive complexes or is prevented from forming such complexes (Bagchi et al. 1991; Chellappan et al. 1991; Chittenden et al. 1991; Murdryj et al. 1991; Phelps et al. 1991). The early region 2 promoter of the Ad DNA replication genes and cellular genes responsive to serum stimulation in cells at the $G_{0}$ state such as c-myc, dihydrofolate reductase (DHFR), and
DNA polymerase $\alpha$ genes are either activated by E2F or contain sequences homologous to the E2F-binding site (Murdryj et al. 1990; Hiebert et al. 1991; Pearson et al. 1991). In differentiating epithelial cells, the cellular replication machinery and attendant processes are shut down, perhaps owing in part to reduced E2F activity, as reported for differentiated F9 teratocarcinoma cells (Reichel et al. 1987). We propose that the reason for the 
increased accumulation of the E6-E7 mRNA in the more differentiated cells in the productive outgrowth and patient samples is because these viral proteins play a role in reactivating host genes required for DNA replication and deoxyribonucleotide biosynthesis in the noncycling and differentiated epithelial cells to support vegetative viral DNA replication.

To examine this hypothesis, we probed by immunocytochemistry the distribution of proliferating cell nuclear antigen (PCNA), which is an accessory protein to DNA polymerase $\delta$. PCNA mRNA is absent in quiescent cells but is induced by serum (Almendral et al. 1987). The monoclonal antibody that we used detects PCNA in all phases of cycling cells; and when this antibody is used on tissues, proliferative cells are antigen positive, whereas differentiated cells are negative (Hall et al. 1990). Induction of PCNA antigen was reproducibly observed in the more differentiated cells in the productive cyst explant raft culture (Fig. 8A) but not in the comparable upper strata cells in the nonproductive cyst outgrowth (Fig. 8B) nor in the control raft culture developed from uninfected foreskin chips (Fig. 8C). In contrast, PCNA antigen was present in some basal cells in all three raft cultures, as expected. Although these results do not prove that E6 or E7 protein induces PCNA gene expression directly, they are consistent with a recent report that the PCNA promoter is activated by the Ad E1A 12S protein (Morris and Mathews 1991), which has a target promoter specificity similar to the HPV E7 protein (Phelps et al. 1991). We emphasize that our hypothesis is compatible with the mechanism proposed for keratinocyte immortalization by the HPV E6 and E7 proteins, as their overexpression in stem cells that are still capable of division disrupts the normal regulation of the cell cycle involving $\mathrm{pRB}$ and $\mathrm{p} 53$, leading to neoplastic proliferation.

In summary, our results demonstrate that appropriately prepared raft cultures can support the papillomavirus productive program, leading to virion assembly, and that no additional factors supplied by a living individual appear to be required. This culture system should enable genetic dissections of viral genes in the context of the viral productive program by transfections with cloned DNAs. The ability to modulate the viral infectious program offers an opportunity to study their regulation not possible in vivo. The explant raft culture system should also be useful for testing potential pharmacological inhibitors of HPV infection. Finally, the tissue explant system should be applicable to investigations of other epitheliotrophic infectious microbes that are difficult to study.

\section{Materials and methods}

\section{Experimental condylomata and raft cultures}

HPV-11 (Hershey isolate) virion extracts were kindly provided by Dr. John W. Kreider. Neonatal foreskin chips were infected with virus extracts that have been serially passaged in foreskin xenografts implanted in nude mice, as described previously (Kreider et al. 1987). For raft cultures, condylomatous cysts that

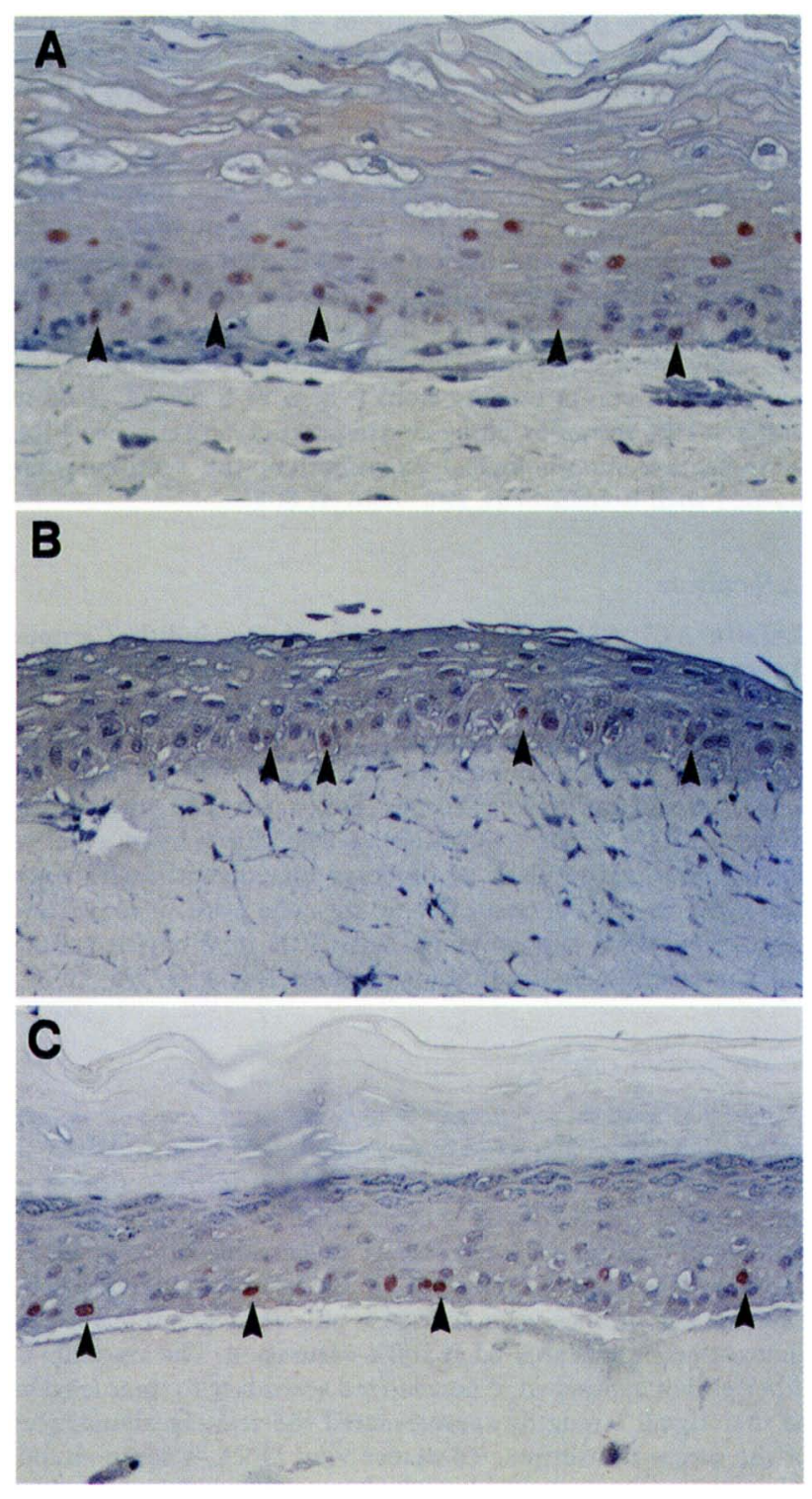

Figure 8. PCNA expression in raft cultures of cyst explants and uninfected foreskin. Formalin-fixed sections were probed for PCNA with PC10 monoclonal antibody and counterstained with hematoxylin. The experiments were performed four times, and the results were consistent. The pictures shown are all from a single experiment. Arrowheads indicate positive nuclear signals seen in the basal cells of all three cultures. (A) Three-week cyst explant raft culture supported by mouse 3T3 A31 fibroblasts. Nuclear staining is also seen in the more superficial differentiated keratinocytes. (B) Three-week cyst explant raft culture supported by human fibroblasts. (C) Three-week uninfected foreskin explant supported by mouse 3T3 A31 fibroblasts. The signal is limited to basal nuclei in $B$ and $C$.

had developed in nude mice for 6-9 months were recovered. The outer, live cell portions of the cyst were cut into $2-\mathrm{mm}^{2}$ chips and placed onto a collagen matrix that was prepared as described (McCance et al. 1988), with modifications as follows: To each milliliter of rat tail collagen type I (Collaborative Research, Inc.) 
were added the buffers and $3 \times 10^{5}$ to $4 \times 10^{5} \mathrm{BALB} / \mathrm{c} 3 \mathrm{~T} 3 \mathrm{~A} 31$ mouse cells or primary neonatal foreskin fibroblasts. One and one-half milliliters of this solution was added to each $2.5-\mathrm{cm}$ well in 12 -well culture plates, allowed to solidify at $37^{\circ} \mathrm{C}$, and fed raft culture medium. Collagen matrices were then raised to the medium-air interface on stainless-steel grids placed in 60$\mathrm{mm}$ culture dishes. Four or five cyst chips were placed on the dermal equivalent, and the cultures were fed every other day with raft culture medium. The bottom of the dish was changed weekly to remove fibroblasts that were shed from the matrix and grew on the plastic. The raft cultures were collected at several time points ranging from 9 days to 6 weeks, fixed in buffered $10 \%$ formalin, embedded in paraffin, and cut into $4-\mu \mathrm{m}$ sections. For morphological examination, the sections were stained with hematoxylin and eosin (H \& E).

\section{Cell culture}

BALB/c 3T3 A31 cells were a gift of Dr. Judith Campisi (Lawrence Berkeley Laboratory), and were propagated in Dulbecco's modified Eagle medium (DMEM) supplemented with $10 \%$ bovine calf serum. Neonatal foreskin fibroblasts were recovered as follows. Minced foreskin tissue was treated with $0.25 \%$ trypsin and $1 \mathrm{~mm}$ EDTA in Hank's balanced salt solution without $\mathrm{Ca}^{2+}$ or $\mathrm{Mg}^{2+}(\mathrm{GIBCO})$ at $37^{\circ} \mathrm{C}$ for $1 \mathrm{hr}$ in a Bellco 125-ml trypsinizing flask while being mixed gently with a stir bar. After removal of tissue debris, the cells were quenched and plated in DMEM supplemented with $10 \%$ fetal bovine serum. Early passages were used in raft cultures.

\section{In situ hybridization}

Whole genomic or exon-specific subgenomic clones in pGEM vectors have been described (Stoler and Broker 1986; Stoler et al. 1989). Riboprobes were synthesized by in vitro transcription in the presence of ${ }^{3} \mathrm{H}$-labeled UTP or CTP or ${ }^{35} \mathrm{~S}$-labeled UTP. In situ hybridization was performed as described (Stoler et al. 1989; Angerer and Angerer 1991). To detect viral transcripts, exon-specific probes with antisense polarity were applied. The shortest probe was applied at $100 \%$ saturation. The amounts of other probes applied were normalized according to their lengths so that signal strengths approximated the relative abundances of the target transcripts. To detect viral DNA, a sense-strand, whole genomic probe was applied to sections that were first heated to $65^{\circ} \mathrm{C}$ in $95 \%$ formamide and $0.1 \times$ SSC for $15 \mathrm{~min}$ to denature the DNA in the section. The slides were dipped in Kodak NTB-2 emulsion and exposed for 1 week when using ${ }^{35} \mathrm{~S}$-labeled probes or for 4 weeks when using ${ }^{3} \mathrm{H}$-labeled probes. After photographic development, the slides were stained lightly with $\mathrm{H} \& \mathrm{E}$ to reveal tissue morphology. The samples were photographed under bright-field illumination for histology and under dark-field illumination to provide maximal signal definition.

Riboprobes for human keratin 1 and keratin 5 were derived from the unique $3^{\prime}$-untranslated regions of cDNAs (Steinert et al. 1985; Eckert and Rorke 1988). The profilaggrin probe corresponds to one coding unit (P. Fleckman, Paul Haydock, and R. Presland, pers. comm.). They do not cross-hybridize to each other or to other keratin genes and have been described previously (Wilson et al. 1992).

\section{PCR amplification of CDNA}

Several 4- $\mu \mathrm{m}$ raft culture sections were scraped off glass slides with razor blades and were deparaffinized with xylene, which was then removed with ethanol. The dry tissue chips were re- suspended in $20 \mathrm{~mm}$ Tris- $\mathrm{Cl}(\mathrm{pH} 8.4), 50 \mathrm{mM} \mathrm{KCl}, 2.5 \mathrm{~mm}$ $\mathrm{MgCl}_{2}, 0.1 \mathrm{mg} / \mathrm{ml}$ of bovine serum albumin, and $2.5 \mathrm{~mm}$ each of the four deoxyribonucleoside triphosphates for the first-strand cDNA synthesis with Moloney murine leukemia virus reverse transcriptase and random hexamers as primers. An aliquot of the reaction mixture was then used for 30 cycles of PCR amplification using TaqI DNA polymerase (Cetus) with primers flanking the known HPV-11 splice sites, as described previously (Chiang et al. 1991). The sense-strand upstream primer spans nucleotides 5' 812-831 $3^{\prime}$ and the antisense-strand downstream primer spans nucleotides $3^{\prime} 3500-35195^{\prime}$. In the negative control, tissue sections were omitted from the reaction mixture. The positive control used linearized Eli ${ }^{\wedge} \mathrm{E} 4$ or E5 cDNA plasmid as template in the PCR reaction. Reaction products were electrophoresed in $1.2 \%$ agarose and visualized by ethidium bromide staining.

\section{Immunocytochemistry}

Formalin-fixed, paraffin-embedded $4-\mu \mathrm{m}$ sections of cyst explant raft culture were deparaffinized with xylene and rehydrated through graded ethanol solutions. Group-specific polyclonal antibody against $\mathrm{L} 1$ capsid antigen was applied according to the manufacturer (DAKO Corp.). Polyclonal antibodies (T. Ho, D. Strike, L. Chow, and T. Broker, unpubl.| raised in rabbits against HPV-11 E4 protein expressed in Escherichia coli (Chow et al. 1987a) were applied at 700- to 1000-fold dilutions. PC10, a monoclonal antibody against human PCNA (DAKO Corp.) was applied at a $1: 20$ dilution. Secondary antibody was either biotinylated goat anti-rabbit (Sigma) or rabbit anti-rat (Vector). Reactivity was detected by using horseradish peroxidasestreptavidin conjugate (Jackson Laboratories for PCNA; Zymed Laboratories for L1 and E4 antibodies) with aminoethylcarbazole as a chromogen, as described (Harlow and Lane 1988). The sections were then counterstained with hematoxylin.

\section{Acknowledgments}

This research was supported by grant 2550 from The Council for Tobacco Research (USA) and U.S. Public Health Service research grant CA36200 to L.T.C. and T.R.B., and a Wilmot Cancer Research Fellowship to L.M.D. We thank Karen Jensen for electron microscopy and the Surgical Pathology Laboratory of Strong Memorial Hospital for the embedding and sectioning of raft cultures. We thank Drs. Philip Fleckman, Paul Haydock, and Richard Presland for providing the profilaggrin probe before publication.

The publication costs of this article were defrayed in part by payment of page charges. This article must therefore be hereby marked "advertisement" in accordance with 18 USC section 1734 solely to indicate this fact.

\section{References}

Almendral, J.M., D. Huebsch, P.A. Blumdell, H. MacdonaldBravo, and R. Bravo. 1987. Cloning and sequence of the human nuclear protein cyclin: Homology with DNA binding proteins. Proc. Natl. Acad. Sci. 84: 1575-1579.

Angerer, L.M. and R.C. Angerer. 1991. Localization of mRNAs by in situ hybridization. Methods Cell Biol. 35: 37-71.

Asselineau, D. and M. Prunieras. 1984. Reconstruction of "simplified" skin: Control of fabrication. Brit. J. Dermatol. 111: 219-222.

Bagchi, S., R. Weinmann, and P. Raychaudhuri. 1991. The retinoblastoma protein copurifies with E2F-I, an E1A-regulated 
inhibitor of the transcription factor E2F. Cell 65: 1063-1072.

Barbosa, M.S., C. Edmonds, C. Fisher, I.T. Schiller, D.R. Lowy, and K.H. Vousden. 1990. The region of HPV E7 oncoprotein homologous to adenovirus $\mathrm{E} 1 \mathrm{a}$ and SV40 large $\mathrm{T}$ antigen contains separate domains for $\mathrm{Rb}$ binding and casein kinase II phosphorylation. EMBO J. 9: 153-160.

Bedell, M.A., J.B. Hudson, T.R. Golub, M.E. Turyk, M. Hosken, G.D. Wilbanks, and L.A. Laimins. 1991. Amplification of human papillomavirus genomes in vitro is dependent on epithelial differentiation. J. Virol. 65: 2254-2260.

Beyer-Finkler, E., M.H. Stoler, F. Girardi, and H. Pfister. 1990. Cell differentiation-related gene expression of human papillomavirus 33. Med. Microbiol. Immunol. 179: 185-192.

Blanton, R.A., N. Peres-Reyes, D.T. Merrick, and J.K. McDougall. 1991. Epithelial cells immortalized by human papillomaviruses have premalignant characteristics in organotypic culture. Am. J. Pathol. 138: 673-685.

Breitburd, F., O. Croissant, and G. Orth. 1987. Expression of human papillomavirus type-1 E4 gene products in warts. Cancer Cells 5: 115-122.

Bretschneider, A., W. Burns, and A. Morrison. 1981. "Pop-off" technic. The ultrastructure of paraffin-embedded sections. Am. J. Clin. Pathol. 76: 450-453.

Broker, T.R., L.T. Chow, M.T. Chin, C.R. Rhodes, S.M. Wolinsky, A. Whitbeck, and M.H. Stoler. 1989. A molecular portrait of human papillomavirus carcinogenesis. Cancer Cells 7: 197-208.

Brown, D.R., M.T. Chin, and D.G. Strike. 1988. Identification of human papillomavirus type $11 \mathrm{E} 4$ gene products in human tissue implants from athymic mice. Virology 165: 262-267.

Chellappan, S.P., S. Hiebert, M. Murdryj, J.M. Horowitz, and J.R. Nevins. 1991. The E2F transcription factor is a cellular target for the RB protein. Cell 65: 1053-1061.

Chen, S.-L. and P. Mounts. 1990. Transforming activity of E5a protein of human papillomavirus type 6 in NIH 3T3 and C127 cells. J. Virol. 64: 3226-3233.

Chittenden, T., D.M. Livingston, and W.G. Kaelin Jr. 1991. The $\mathrm{T} / \mathrm{E} 1 \mathrm{~A}$ binding domain of the retinoblastoma product can interact selectively with a sequence-specific DNA-binding protein. Cell 65: 1073-1082.

Chiang, C.-M., T.R. Broker, and L.T. Chow. 1991. An E1M ^E2C fusion protein encoded by human papillomavirus type 11 is a sequence-specific transcription repressor. I. Virol. 65: 3317-3329.

Chiang, C.-M., M. Ustav, A. Stenlund, T.F. Ho, T.R. Broker, and L.T. Chow. 1992. Viral E1 and E2 proteins support replication of homologous and heterologous papillomaviral origins. Proc. Natl. Acad. Sci. 89 (in press).

Chow, L.T., H. Hirochika, M. Nasseri, M.H. Stoler, S.M. Wolinsky, M.T. Chin, R. Hirochika, D.S. Arvan, and T.R. Broker. 1987a. Human papillomavirus gene expression. Cancer Cells 5: 55-72.

Chow, L.T., M. Nasseri, S.M. Wolinsky, and T.R. Broker. $1987 \mathrm{~b}$. Human papillomavirus types 6 and 11 mRNAs from genital condylomata. I. Virol. 61: 2581-2588.

Compton C.C., J.M. Gill, D.A. Bradford, S. Regauer, G.G. Gallico, and N.E. O'Connor. 1989. Skin generated from cultured epithelial autografts on full-thickness burn wounds from 6 days to 5 years after grafting. Lab. Invest. 60: 600-612.

Crook, T., J. Tidy, and K.H. Vousden. 1991. Degradation of p53 can be targeted by HPV E6 sequences distinct from those required for p53 binding and trans-activation. Cell 67: 547556.

Crum, C.P., S. Barber, M. Symbula, K. Snyder, A. M. Saleh, and J.K. Roche. 1990. Coexpression of human papillomavirus type $16 \mathrm{E} 4$ and $\mathrm{L} 1$ open reading frames in early cervical neo- plasia. Virology 178: 238-246.

de Villiers, E.-M. 1989. Heterogeneity of human papillomavirus groups. J. Virol. 63: 4898-4903.

Doorbar, J., D. Campbell, R.J.A. Grand, and P.H. Gallimore. 1986. Identification of the human papilloma vinus-1a E4 gene products. $E M B O$ J. 5: 355-362.

Doorbar, J., A. Parton, K. Hartley, L. Banks, T. Crook, M. Stanley, and L. Crawford. 1990. Detection of novel splicing patterns in a HPV16-containing keratinocyte cell line. Virology 178: 254-262.

Doorbar, J., S. Ely, C. McLean and L. Crawford. 1991. Specific interaction between HPV-16 E1-E4 and cytokeratins results in collapse of the epithelial cell intermediate filament network. Nature 352: 824-827.

Dunn, A.E. and M.M. Ogilvie. 1968. Intranuclear virus particles in human genital wart tissue: Observations on the ultrastructure of the epidermal layer. /. Ultrastruct. Res. 22: 282295.

Eckert, R.L. and E.A. Rorke. 1988. The sequence of the human epidermal $58-\mathrm{kD}$ ( 5) type II keratin reveals an absence of $5^{\prime}$ upstream sequence conservation between coexpressed epidermal keratins. DNA 7: 337-345.

Fujimura, F.K., P.E. Silbert, W. Eckart, and E. Linney. 1981. Polyoma virus infection of retinoic acid-induced differentiated teratocarcinoma cells. J. Virol. 39: 306-312.

Halbert, C.L., G.W. Demers, and D.A. Galloway. 1991. The E7 gene of human papillomavirus type 16 is sufficient for immortalization of human epithelial cells. I. Virol. 65: 473478.

Hall, P.A., D.A. Levison, A.L. Woods, C.C.-W. Yu, D.B. Kellock, J.A. Watkins, D.M. Barnes, C.E. Gillett, R. Camplejohn, R. Dover, N.H. Waseem, and D.P. Lane. 1990. Proliferating cell nuclear antigen (PCNA) immunolocalization in paraffin sections: An index of cell proliferation with evidence of deregulated expression in some neoplasms. I. Pathol. 162: 285294.

Harlow, E. and D. Lane. 1988. Antibodies: A laboratory manual. Cold Spring Harbor Laboratory, Cold Spring Harbor, New York

Hawley-Nelson, P., K.H. Vousden, N.I. Hubbert, D.R. Lowy, and J.T. Schiller. 1989. HPV16 E6 and E7 cooperate to immortalize human foreskin keratinocytes. EMBO I. 8: 39053910.

Hiebert, S.W., M. Blake, J. Azizkhan, and J.R. Nevins. 1991. Role of E2F transcription factor in E1A-mediated trans activation of cellular genes. $J$. Virol. 65: 3547-3552.

Hills, E. and C.R. Laverty. 1979. Electron microscopic detection of papillomavirus particles in selected koilocytotic cells in a routine cervical smear. Acta Cytol. 23: 53-56.

Hudson, J.B., M.A. Bedell, D.J. McCance, and L.A. Laimins. 1990. Immortalization and altered differentiation of human keratinocytes in vitro by the E6 and E7 open reading frames of human papillomavirus type 18. J. Virol. 64: 519-526.

Kopan, R., G. Traska, and E. Fuchs. 1987. Retinoids as important regulators of terminal differentiation: Examining keratin expression in individual epidermal cells at various stages of keratinization. J. Cell Biol. 105: 427-440.

Kreider, J.W., M.K. Howett, A.E. Leure-Dupree, R.J. Zaino, and J.A. Weber. 1987. Laboratory production in vivo of infectious human papillomavirus type 11. J. Virol. 61: 590-593.

Leptak, C., S.R. y Cajal, R. Kulke, B.H. Horwitz, D.J. Riese II, G.P. Dotto, and D. DiMaio. 1991. Tumorigenic transformation of murine keratinocytes by the $\mathrm{E} 5$ genes of bovine papillomavirus type 1 and human papillomavirus type 16. $I$. Virol. 65: 7078-7083.

McCance, D.J., R. Kopan, E. Fuchs, and L.A. Laimins. 1988. 
Human papillomavirus type 16 alters human epithelial cell differentiation in vitro. Proc. Natl. Acad. Sci. 85: 71697173.

Morris, G.F. and M.B. Mathews. 1991. The adenovirus E1A transforming protein activates the proliferating cell nuclear antigen promoter via an activating transcription factor site. J. Virol. 65: 6397-6406.

Murdryi, M., S.W. Hiebert, and J.R. Nevins. 1990. A role for the adenovirus inducible E2F transcription factor in a proliferation dependent signal transduction pathway. EMBO $\%$ 9: $2179-2184$

Murdryj, M., S.H. Devoto, S.W. Hiebert, T. Hunter, J. Pines, and J.R. Nevins. 1991. Cell cycle regulation of the E2F transcription factor involves an interaction with cyclin A. Cell 65: 1243-1253.

Münger, K., W.C. Phelps, V. Bubb, P.M. Howley, and R. Schlegel. 1989a. The E6 and E7 genes of the human papillomavirus type 16 together are necessary and sufficient for transformation of primary human keratinocytes. I. Virol. 63: 4417-4421.

Münger, K., B.A. Werness, N. Dyson, W.C. Phelps, E. Harlow, and P.M. Howley. 1989b. Complex formation of human papillomavirus $\mathrm{E} 7$ proteins with the retinoblastoma tumor suppressor gene product. EMBO J. 8: 4099-4105.

Nasseri, M., R. Hirochika, T.R. Broker, and L.T. Chow. 1987. A human papilloma virus type 11 transcript encoding an El `E4 protein. Virology 159: 433-439.

Palermo-Dilts, D.A., T.R. Broker, and L.T. Chow. 1990. Human papillomavirus type 1 produces redundant as well as polycistronic mRNAs in plantar warts. J. Virol. 64: 3144-3149.

Parenteau, N.L., C.M. Nolte, P. Bilbo, M. Rosenberg, L.M. Wilkins, E.W. Johnson, S. Watson, V.S. Mason, and E. Bell. 1991. Epidermis generated in vitro: Practical considerations and applications. I. Cell. Biochem. 45: 245-251.

Pearson, B.E., H.P. Nasheuer, and T.S. Wang. 1991. Human DNA polymerase $\alpha$ gene: Sequences controlling expression in cycling and serum-stimulated cells. Mol. Cell. Biol. 11: 2081-2085.

Phelps, W.C., S. Bagchi, J.A. Barnes, P. Raychaudhuri, V. Kraus, K. Münger, P.M. Howley, and J.R. Nevins. 1991. Analysis of trans activation by human papillomavirus type $16 \mathrm{E} 7$ and adenovirus $12 \mathrm{~S}$ E1A suggests a common mechanism. J. Virol. 65: 6922-6930.

Reichel, R., I. Kovesdi, and J.R. Nevins. 1987. Developmental control of a promoter-specific factor that is also regulated by the E1A gene product. Cell 48: 501-506.

Rohlfs, M., S. Winkenbach, S. Meyer, T. Rupp, and M. Dürst. 1991. Viral transcription in human keratinocyte cell lines immortalized by human papillomavirus type-16. Virology 183: 331-342.

Rotenberg, M.O., C.-M. Chiang, M. Schweitz, T.R. Broker, and L.T. Chow. 1989a. Characterization of cDNAs of spliced HPV-11 E2 mRNA and other HPV mRNAs recovered via retrovirus-mediated gene transfer. Virology 172: 468-478.

Rotenberg, M.O., L.T. Chow, and T.R. Broker. 1989b. Characterization of rare human papillomavirus type 11 mRNAs coding for regulatory and structural proteins by the polymerase chain reaction. Virology 172: 489-497.

Smotkin, D., H. Prokoph, and F.O. Wettstein. 1989. Oncogenic and nononcogenic human genital papillomaviruses generate the E7 m'RNA by different mechanisms. /. Virol. 63: 14411447.

Sousa, R., N. Dostatni, and M. Yaniv. 1990. Control of papillomavirus gene expression. Biochim. Biophys. Acta 1032: 19 37.

Steinert, P.M., D.A.D. Parry, W.W. Idler, L.D. Johnson, A.C.
Steven, and D.R. Roop. 1985. Amino acid sequences of mouse and human epidermal type II keratins of $M_{r} 67,000$ provide a systematic basis for the structural and functional diversity of the end domains of keratin intermediate filament subunits. J. Biol. Chem. 260: 7142-7149.

Sterling, J., M. Stanley, G. Gatward, and T. Minson. 1990. Production of human papillomavirus type 16 virions in a keratinocyte cell line. J. Virol. 64: 6305-6307.

Stoler, M.H. and T.R. Broker. 1986. In situ hybridization detection of human papilloma virus DNA and messenger RNA in genital condylomas and a cervical carcinoma. Hum. Pathol. 17: $1250-1258$.

Stoler, M.H., S.M. Wolinsky, A. Whitbeck, T.R. Broker, and L.T. Chow. 1989. Differentiation-linked human papillomavirus types 6 and 11 transcription in genital condylomata revealed by in situ hybridization with message-specific RNA probes. Virology 172: 331-340.

Stoler, M.H., A. Whitbeck, S.M. Wolinsky, T.R. Broker, L.T. Chow, M.K. Howett, and J.W. Kreider. 1990. Infectious cycle of human papillomavirus type 11 in human foreskin xenografts in nude mice. $J$. Virol. 64: 3310-3318.

Stoler, M.H., C.R. Rhodes, A. Whitbeck, S. Wolinsky, L.T. Chow, and T.R. Broker. 1992. Gene expression of human papillomavirus type 16 and 18 in cervical neoplasias. Hum. Pathol. 23: 117-128.

Taichman, L.B. and R.F. LaPorta. 1987. The expression of papillomaviruses in epithelial cells. Papovaviridae 2: 109-140.

Tooze, J. 1981. DNA tumor viruses, 2nd ed., revised. Cold Spring Harbor Laboratory, Cold Spring Harbor, New York.

Ustav, M. and A. Stenlund. 1991. Transient replication of BPV-1 requires two viral polypeptides encoded by the E1 and E2 open reading frames. EMBO $/$. 10: 449-457.

Ward, P. and P. Mounts. 1989. Heterogeneity in mRNA of human papillomavirus type- 6 subtypes in respiratory tract lesions. Virology 168: 1-12.

Werness, B.A., A.J. Levine, and P.M. Howley. 1990. Association of human papillomavirus type 16 and 18 E6 proteins with p53. Science 248: 76-79.

Wilson, J.L., S.C. Dollard, L.T. Chow, and T.R. Broker. 1992. Epithelial-specific gene expression during differentiation of stratified primary human keratinocyte cultures. Cell Growth Differ. 8 (in press).

Woodworth, C.D., S. Cheng, S. Simpson, L. Hamacher, L.T. Chow, T.R. Broker, and J.A. DiPaolo. 1992. Recombinant retroviruses encoding human papillomavirus type $18 \mathrm{E} 6$ and E7 genes stimulate cellular proliferation and suppress squamous differentiation in human keratinocytes in vitro. Oncogene 7: 619-626.

Yang, Y.-C., B.A. Spalholz, M.S. Rabson, and P.M. Howley. 1985. Dissociation of transforming and trans-activation functions for bovine papillomavirus type 1. Nature 318: $575-577$.

Yang, L., R. Li, I.J. Mohr, R. Clark, and M.R. Botchan. 1991. Activation of BPV-1 replication in vitro by the transcription factor E2. Nature 353: 628-632. 


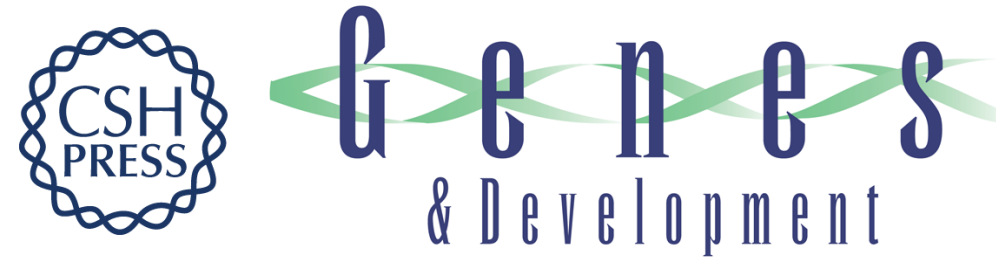

\section{Production of human papillomavirus and modulation of the infectious program in epithelial raft cultures. OFF.}

S C Dollard, J L Wilson, L M Demeter, et al.

Genes Dev. 1992, 6:

Access the most recent version at doi:10.1101/gad.6.7.1131

References This article cites 67 articles, 24 of which can be accessed free at: http://genesdev.cshlp.org/content/6/7/1131.full.html\#ref-list-1

License

Email Alerting

Service

Receive free email alerts when new articles cite this article - sign up in the box at the top right corner of the article or click here.

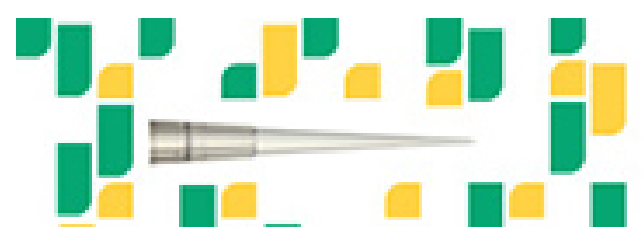

Focused on your science. 